\title{
ABCB1 as predominant resistance mechanism in cells with acquired SNS-032 resistance
}

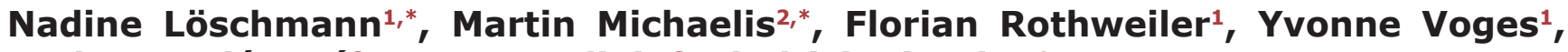 \\ Barbora Balónová ${ }^{3}$, Barry A. Blight ${ }^{3}$, Jindrich Cinatl Jr ${ }^{1}$ \\ ${ }^{1}$ Institut für Medizinische Virologie, Klinikum der Goethe-Universität, 60596 Frankfurt am Main, Germany \\ ${ }^{2}$ Centre for Molecular Processing and School of Biosciences, University of Kent, Canterbury, UK \\ ${ }^{3}$ School of Physical Sciences, University of Kent, Canterbury, UK \\ *These authors equally contributed to this work
}

Correspondence to: Jindrich Cinatl Jr, email: Cinatl@em.uni-frankfurt.de

Keywords: $A B C B 1, C D K$ inhibitor, multi-drug resistance, neuroblastoma, cancer

Received: February 19, 2016 Accepted: July 27, $2016 \quad$ Published: August 09, 2016

\section{ABSTRACT}

The CDK inhibitor SNS-032 had previously exerted promising anti-neuroblastoma activity via CDK7 and 9 inhibition. ABCB1 expression was identified as major determinant of SNS-032 resistance. Here, we investigated the role of ABCB1 in acquired SNS-032 resistance. In contrast to ABCB1-expressing UKF-NB-3 sublines resistant to other ABCB1 substrates, SNS-032-adapted UKF-NB-3 (UKF-NB-

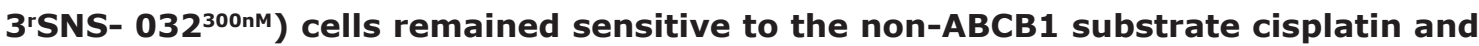
were completely re-sensitized to cytotoxic $A B C B 1$ substrates by $A B C B 1$ inhibition. Moreover, UKF-NB-3rSNS- $032^{300 n M}$ cells remained similarly sensitive to CDK7 and 9 inhibition as UKF-NB-3 cells. In contrast, SHEPrSNS-032 ${ }^{2000 n M}$, the SNS-032-resistant sub-line of the neuroblastoma cell line SHEP, displayed low level SNS-032 resistance also when ABCB1 was inhibited. This discrepancy may be explained by the higher SNS-032 concentrations that were used to establish SHEPrSNS-032 ${ }^{2000 \mathrm{nM}}$ cells, since SHEP cells intrinsically express ABCB1 and are less sensitive to SNS-032 (IC $912 \mathrm{nM}$ ) than UKF-NB-3 cells $\left(\mathrm{IC}_{50} 153 \mathrm{nM}\right)$. In conclusion, we show that ABCB1 expression represents the primary (sometimes exclusive) resistance mechanism in neuroblastoma cells with acquired resistance to SNS-032. Thus, ABCB1 inhibitors may increase the SNS-032 efficacy in ABCB1-expressing cells and prolong or avoid resistance formation.

\section{INTRODUCTION}

Neuroblastoma is the most frequent solid extracranial pediatric cancer. About half of the patients are diagnosed with high-risk disease associated with overall survival rates below $50 \%$ despite myeloablative therapy and differentiation therapy using retinoids $[1,2]$.

SNS-032 (BMS-387032) is a cyclin-dependent kinase 2 (CDK2), 7 , and 9 inhibitor under pre-clinical and clinical investigation for a wide range of solid and hematologic malignancies [3-16] including neuroblastoma [17-19]. The compound was initially introduced as N-acyl-2-aminothiazole inhibitor of CDK2 [3]. The relevance of CDK2, CDK7, and/ or CDK9 as crucial SNS-032 drug targets differs between different cancer cell types $[4,7-9,12,19]$. We recently showed that therapeutic SNS-032 concentrations exerted antineuroblastoma effects in a panel of 109 neuroblastoma cell lines (19 parental neuroblastoma cell lines, 90 sublines with acquired resistance to 14 different anti-cancer drugs) and in primary neuroblastoma cells [19]. SNS032 further inhibited tumor growth in a chemoresistant neuroblastoma xenograft model [19]. Interference with CDK7 and CDK9 appeared to be critical for the antineuroblastoma effects of SNS-032 [19].

SNS-032 had further been speculated to interfere with ABCB1 (also known as P-glycoprotein or MDR1) [20]. Our report (published on the 1st December 2013) 
[19] and another report (published on 23rd December 2013) [21] confirmed this assumption. ABCB1 expression was the dominant SNS-032-resistance mechanism in neuroblastoma cells from a panel of 109 neuroblastoma cell lines [19]. Only ABCB1-expressing neuroblastoma cell lines were insensitive to therapeutically achievable SNS-032 concentrations. In the presence of ABCB1 inhibitors, all 30 ABCB1-expressing neuroblastoma cell lines displayed SNS-032 $\mathrm{IC}_{50}$ values in the range of therapeutic SNS-032 concentrations [19].

Here, we established and characterized SNS-032resistant sub-lines of the MYCN-amplified, ABCB1negative neuroblastoma cell line UKF-NB-3 (UKFNB- $3^{\text {rSNS}}-032^{300 \mathrm{nM}}$ ) and the non-MYCN-amplified, ABCB1-expressing neuroblastoma cell line SHEP (SHEPrSNS-032 2000nM) to analyze the role of ABCB1 in neuroblastoma models of acquired SNS-032 resistance.

\section{RESULTS}

\section{Enhanced ABCB1 expression in the SNS-032- resistant UKF-NB-3 sub-line UKF-NB-3 ${ }^{\text {rSNS- }}$ $032^{300 n M}$}

UKF-NB-3 cells were adapted to growth in the presence of SNS-032 $300 \mathrm{nM}$ by step-wise increase of the SNS-032 concentration. No pre-existing resistant sub-population could be selected by directly applying SNS-032 $300 \mathrm{nM}$. The SNS-032 IC $_{50}$ value was four times higher in SNS-032-adapted UKF-NB-3 ${ }^{\mathrm{r} S N S}-032^{300 \mathrm{nM}}$ cells $(606.7 \mathrm{nM})$ than in UKF-NB-3 cells $(152.6 \mathrm{nM})$. UKF-NB-3 and its SNS-032-resistant sub-line UKF-NB$3^{\mathrm{r} S N S}-032^{300 \mathrm{nM}}$ were characterized by similar doubling times (UKF-NB-3: $26.6 \pm 8.2$ h, UKF-NB-3 ${ }^{\text {rSNS-032 }} 2^{300 \mathrm{nM}}$ $32.9 \pm 12.8 \mathrm{~h}$ ) and a similar morphology (Supplementary Figure S1). However, UKF-NB-3 ${ }^{\mathrm{r} S N S}-032^{300 \mathrm{nM}}$ cells displayed elevated ABCB1 levels relative to UKF-NB-3 cells (Figure 1, Supplementary Figure S2). We had previously shown that SNS-032 is also a substrate of ABCG2 (also known as BCRP) [19]. In contrast, expression of ABCC1 (also known as MRP1), another relevant $\mathrm{ABC}$ transporter known to be involved in cancer cell drug resistance in various cancer entities including neuroblastoma [22], did not influence anti-cancer activity of SNS-032 (Supplementary Figure S3). We did neither detect increased ABCG2 nor ABCC1 expression in UKF-NB$3^{\mathrm{r} S N S}-032^{300 \mathrm{nM}}$ cells (Figure 1, Supplementary Figure S2).

\section{Sensitization of $\mathrm{ABCB} 1-$ expressing drug- resistant UKF-NB-3 sub-lines to SNS-032 and other $\mathrm{ABCB} 1$ substrates by inhibition of $\mathrm{ABCB} 1$}

UKF-NB-3 ${ }^{\text {rSNS-032 }} 2^{300 \mathrm{nM}}$ cells displayed cross-resistance to the cytotoxic ABCB1 substrates doxorubicin, etoposide, and vincristine (Figure 2, Supplementary Table S1A). The fold changes $\mathrm{IC}_{50}$ resistant UKF-NB-3 ${ }^{\mathrm{r} S N S}-032^{300 \mathrm{nM}} / \mathrm{IC}_{50}$ UKF-NB-3 ranged between 2.0 (etoposide) and 10.8 (vincristine) (Figure 3, Supplementary Table S1A). Addition of verapamil $10 \mu \mathrm{M}$, a concentration that did not affect the viability of the investigated cell lines (Supplementary

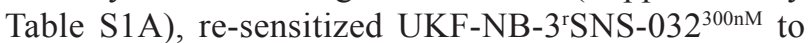
SNS-032 to the level of the parental UKF-NB-3 cells as indicated by a fold change $\mathrm{IC}_{50}$ SNS-032 in UKFNB- $3{ }^{\mathrm{r} S N S}-032^{300 \mathrm{nM}}$ cells in the presence of verapamil/ $\mathrm{IC}_{50}$ SNS-032 in UKF-NB-3 cells below 2 (Figure 3, Supplementary Table S1A). Verapamil also reduced the doxorubicin, etoposide, and vincristine $\mathrm{IC}_{50}$ values in UKF-NB-3 ${ }^{\text {rSNS}}-032^{300 \mathrm{nM}}$ cells to a level similar to UKFNB-3 (Figure 3; Supplementary Table S1A).

To further confirm the role of ABCB1 in UKF-NB$3^{\text {rSNS}}-032^{300 n M}$ cells, we depleted ABCB1 using siRNA. ABCB1 depletion increased SNS-032 sensitivity in UKF-

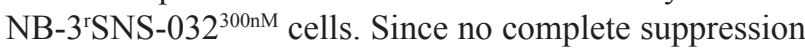
of $\mathrm{ABCB} 1$ expression was achieved by siRNA, the SNS-032 $\mathrm{IC}_{50}$ remained higher than in parental UKFNB-3 cells (Supplementary Table S1B; Supplementary Figure S4). However, the SNS-032 $\mathrm{IC}_{50}$ value could be reduced in UKF-NB- $3^{\mathrm{r} S N S}-032^{300 \mathrm{nM}}$ cells to the level of UKF-NB-3 cells by the use of zosuquidar (Supplementary Table S1C), an alternative ABCB1 inhibitor that structurally differs from verapamil [23].

Moreover, we synthesized a fluorescent SNS032-BODIPY derivative. Flow cytometry experiments indicated, compared to UKF-NB-3, a reduced accumulation of SNS-032-BODIPY in ABCB1-transduced UKF-NB-3 (UKF-NB-3 ${ }^{\mathrm{ABCB} 1}$ ) cells and UKF-NB$3^{\mathrm{r} S N S}-032^{300 \mathrm{nM}}$ cells that could be restored by the use of verapamil (Supplementary Figure S5). Notably, the differences between SNS-032-BODIPY accumulation

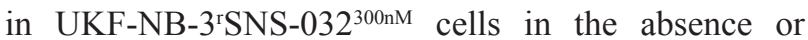
presence of verapamil seemed to be small compared to the differences observed in UKF-NB-3 ${ }^{\mathrm{ABCB} 1}$ cells. However, this appears to reflect the respective discrepancies in the SNS-032 IC $_{50}$ values (UKF-NB-3 ${ }^{\text {rSNS-032 }}{ }^{300 \mathrm{nM}}$ : $607 \mathrm{nM}$; UKF-NB-3 $\left.{ }^{\mathrm{ABCB} 1}: 3885 \mathrm{nM}\right)$.

The doxorubicin-resistant (UKF-NB- $3^{\mathrm{r} D O X^{20}}$ ), etoposide-resistant (UKF-NB- $3^{\mathrm{r}} \mathrm{ETO}^{100}$ ), and vincristineresistant (UKF-NB- $3^{\mathrm{r}} \mathrm{VCR}^{10}$ ) UKF-NB-3 sub-lines that express ABCB1 displayed cross-resistance to SNS-032, doxorubicin, etoposide, and vincristine. Verapamil decreased the SNS-032 $\mathrm{IC}_{50}$ values in all three cell lines to a level similar to UKF-NB-3 as indicated by fold changes (SNS-032 $\mathrm{IC}_{50}$ in resistant cell lines in the presence of verapamil/ SNS-032 $\mathrm{IC}_{50}$ in UKF-NB-3 cells) below 2 (Figure 3, Supplementary Table S1A). However, verapamil did not re-sensitize UKF-NB- $3^{\mathrm{r}} \mathrm{DOX}{ }^{20}$, UKFNB- $3^{r} \mathrm{ETO}^{100}$, or UKF-NB- $3^{\mathrm{r}} \mathrm{VCR}^{10}$ cells to doxorubicin, etoposide, or vincristine to the level of UKF-NB-3 cells (Figure 3, Supplementary Table S1A). The only exemption was the vincristine sensitivity of UKF-NB- $3^{\mathrm{r}} \mathrm{ETO}^{100}$ cells (Figure 3, Supplementary Table S1A). 


\section{Cross-resistance of $\mathrm{ABCB} 1$-expressing drug- resistant UKF-NB-3 sub-lines to the non-ABCB1 substrate cisplatin and of the cisplatin-resistant UKF-NB-3 sub-line UKF-NB-3 ${ }^{\mathrm{r}} \mathrm{CDDP}^{1000}$ to ABCB1 substrates}

We next determined the resistance profile to cisplatin that is not an ABCB1 substrate. UKF-NB-3rSNS-032 $2^{300 \mathrm{nM}}$ and UKF-NB-3 $3^{\mathrm{r}} \mathrm{ETO}^{100}$ did not display cisplatin resistance (cisplatin $\mathrm{IC}_{50}$ resistant UKF-NB-3 sub-line/ cisplatin $\mathrm{IC}_{50}$ UKF-NB-3 $<2$ ). In contrast, UKF-NB-3 $3^{\mathrm{r}} \mathrm{DOX}^{20}$ and UKFNB-3 ${ }^{r} \mathrm{VCR}^{10}$ cells were substantially less sensitive to cisplatin than UKF-NB-3 cells (Figure 4A; Supplementary Table S1D).

UKF-NB-3 ${ }^{\mathrm{r}} \mathrm{CDDP}^{1000}$ cells displayed profound cisplatin resistance (cisplatin $\mathrm{IC}_{50}$ : UKF-NB-3, $280 \mathrm{nM}$; UKF-NB-3 ${ }^{\mathrm{r} C D D P}{ }^{1000}, 8936 \mathrm{nM}$, Supplementary Table S1D) and cross-resistance (fold change $\mathrm{IC}_{50}$ UKF-NB$3^{\mathrm{r}} \mathrm{CDDP}^{1000 /} \mathrm{IC}_{50}$ UKF-NB-3 $\geq 2$ ) to doxorubicin (fold change 4.0) and vincristine (fold change 3.3) but not to SNS-032 (fold change 0.8 ) or etoposide (fold change 1.6) (Figure 4B, Supplementary Table S1E).

\section{CDK7 and CDK9 as drug targets in UKF-NB- $3^{\text {rSNS-032 }}{ }^{300 n M}$ cells}

We had previously shown that SNS-032 reduces the viability of UKF-NB-3 cells via interference with CDK7 and CDK9 and subsequent RNA polymerase II inhibition resulting in depletion of anti-apoptotic proteins with a high turnover rate including Mcl-1, XIAP, and survivin [19].

In the presence of verapamil $10 \mu \mathrm{M}, \mathrm{SNS}-032300 \mathrm{nM}$ exerted similar effects on RNA polymerase II protein levels, RNA polymerase II phosphorylation at Ser-5 (target of CDK7), RNA polymerase II phosphorylation at Ser-2 (target of CDK9) (Figure 5A), RNA polymerase II activity (Figure 5B), and XIAP, Mcl-1, and survivin protein levels (Figure 5A) in UKF-NB-3 ${ }^{\text {SNNS- }} 032^{300 \mathrm{nM}}$ cells as in UKFNB-3 cells.

Moreover, the relative resistances $\mathrm{IC}_{50}$ UKFNB-3 ${ }^{\mathrm{r} S N S}-032^{300 \mathrm{nM}} / \mathrm{IC}_{50}$ UKF-NB-3 were $\leq 1.5$ for the CDK2, 7, and 9 inhibitor seliciclib (also known as roscovitine or CYC202) [24], the CDK9 inhibitor LDC000067 [25], the CDK7 inhibitor BS-181 [26], and

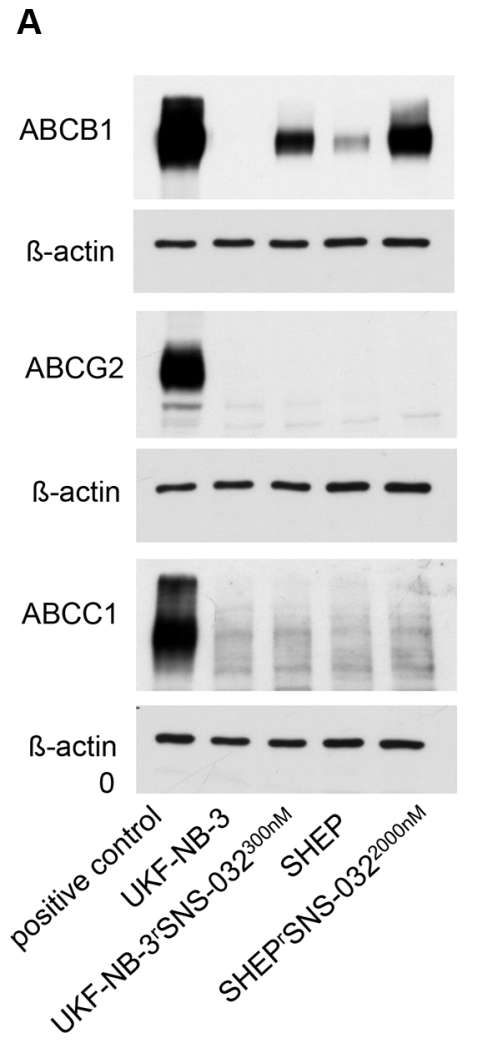

B

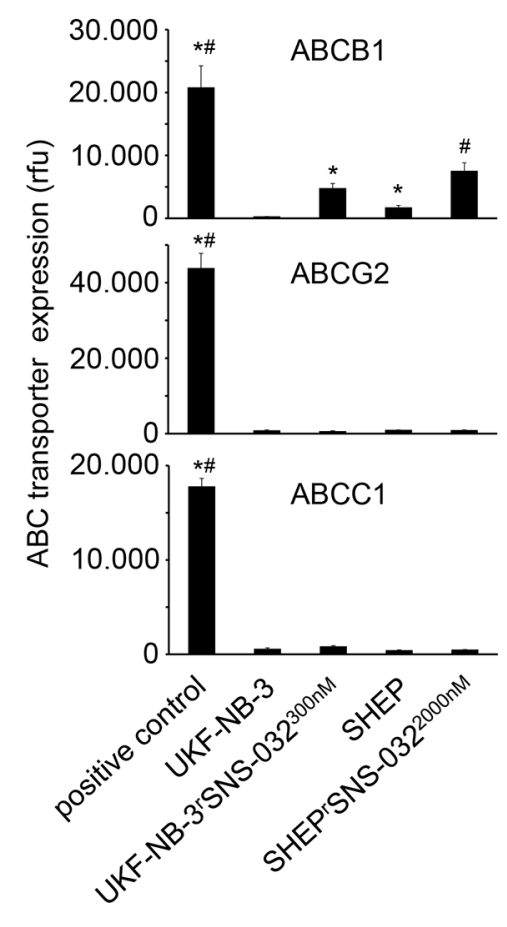

Figure 1: ABC transporter expression levels in in the neuroblastoma cell lines UKF-NB-3 and SHEP and their sublines with acquired resistance to SNS-032 resistance (UKF-NB-3 ${ }^{\text {SSNS-032 }}{ }^{300 \mathrm{nM}}$, SHEPrSNS-032 ${ }^{2000 \mathrm{nM}}$ ). (A) Cropped representative Western blots indicating ABCB1, ABCG2, and ABCC1 levels. (B) ABCB1, ABCG2, and ABCC1 levels detected by flow cytometry and presented as relative fluorescence units (rfu). Representative flow cytometry histograms are presented in Supplementary Figure S2. ${ }^{*} P<0.05$ relative to UKF-NB-3 cells, ${ }^{*} P<0.05$ relative to SHEP. Positive controls were ABCB1-transduced UKF-NB-3 cells for $\mathrm{ABCB} 1, \mathrm{ABCG} 2$-transduced UKF-NB-3 cells for $\mathrm{ABCG} 2$, and $\mathrm{NLF}^{\mathrm{r}} \mathrm{VCR}^{10}$ cells for $\mathrm{ABCC}$. 
the $\mathrm{CDK} 1,2,4,6,7$, and 9 inhibitor alvocidib (also known as flavopiridol or HMR-1275) [27] (Figure 6A; Supplementary Table S1F). Finally, UKF-NB-3 ${ }^{\text {rSNS- }}$ $032^{300 \mathrm{nM}}$ cells were similar sensitive to siRNA-mediated depletion of CDK7 and CDK9 as UKF-NB-3 cells (Figure 6B, Supplementary Table S1G). Hence, UKFNB-3 $3^{\text {rSNS-032 }} 2^{300 \mathrm{nM}}$ cells do not seem to have acquired specific resistance to CDK inhibition.

\section{Investigation of SHEPrSNS-032 2000nM, a SNS-032-} resistant sub-line of the neuroblastoma cell line SHEP

In order to investigate to which extent ABCB1 expression may be a resistance mechanism in an additional model of acquired SNS-032 resistance, we established an SNS-032-resistant SHEP sub-line (SHEPrSNS-032 ${ }^{2000 \mathrm{nM}}$ ). In contrast to the MYCNamplified neuroblastoma cell line UKF-NB-3, SHEP cells do not harbor a MYCN amplification. Also in contrast to UKF-NB-3, SHEP cells express ABCB1 and display a higher SNS-032 $\mathrm{IC}_{50}$ value than UKFNB-3 cells (SHEP 912 nM; UKF-NB-3 153 nM (Supplementary Table S1A, S1H)). SHEP cells were adapted to growth in the presence of SNS$0322000 \mathrm{nM}$ by step-wise increase of the SNS-032 concentration. No pre-existing SNS-032-resistant sub-population could be selected by directly applying SNS-032 2000 nM.

SHEP and SHEPrSNS-032 $2000 \mathrm{nM}$ cells displayed similar doubling times (SHEP: $17.9 \pm 1.4 \mathrm{~h}$, SHEP ${ }^{\mathrm{r}} \mathrm{SNS}-$ $032^{2000 \mathrm{~nm}} 17.9 \pm 0.6 \mathrm{~h}$ ) and a similar morphology
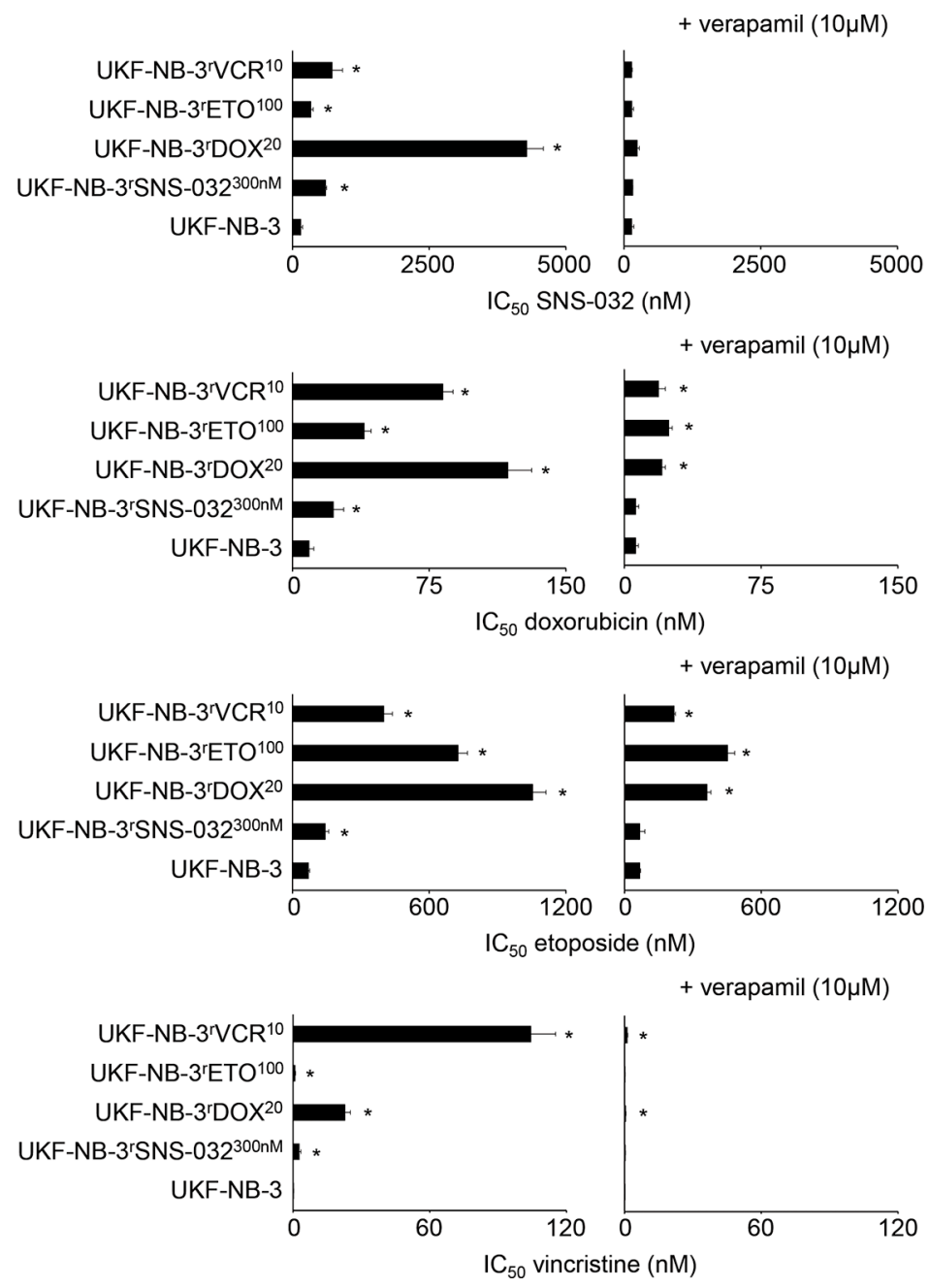

Figure 2: Sensitivity of UKF-NB-3 and its ABCB1-expressing sub-lines with acquired resistance to SNS-032 (UKF-NB-

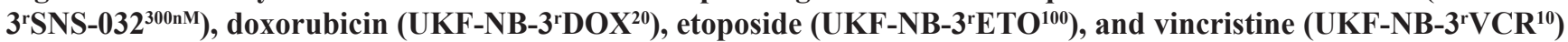
to the cytotoxic $\mathrm{ABCB} 1$ substrates SNS-032, doxorubicin, etoposide, and vincristine in the absence or presence of the ABCB1 inhibitor verapamil. Verapamil alone did not influence cell viability (Supplementary Table S1A). ${ }^{*} P<0.05$ relative to the drug concentration that reduces cell viability by $50 \%\left(\mathrm{IC}_{50}\right)$ in UKF-NB-3 cells. 
(Supplementary Figure S1). Adaptation of SHEP cells to SNS-032 resulted in a further increase of the cellular ABCB1 levels but did not affect ABCG2 or ABCC1 expression levels (Figure 1, Supplementary Figure S2).

Similar to UKF-NB-3 ${ }^{\text {rSNS-032 }} 2^{300 \mathrm{nM}}$ cells, (cross-) resistances predominantly depended on $\mathrm{ABCB} 1$ function in SHEPrSNS-032 $2000 \mathrm{nM}$ cells (Figure 7 and Figure 8A, Supplementary Table S1H and Supplementary Table S1I). $\mathrm{ABCB} 1$ inhibition using verapamil did not always reduce the $\mathrm{IC}_{50}$ values for the ABCB1 substrates to the level of parental SHEP cells in the presence of verapamil. The fold change $\mathrm{IC}_{50}$ SHEPrSNS-032 $2000 \mathrm{nM} / \mathrm{IC}_{50}$ SHEP in the presence of verapamil was close to 2 for SNS-032 (1.98) and doxorubicin (1.96) and above 2 for etoposide (2.87), while it was 1.45 for vincristine (Figure 7, Supplementary Table S1H). For the non-ABCB1 substrate cisplatin and the $\mathrm{CDK}$ inhibitors seliciclib, LDC000067, BS-181, and alvocidib the fold changes $\mathrm{IC}_{50}$ SHEPSNS-032 $^{2000 \mathrm{nM}} / \mathrm{IC}_{50}$ SHEP were clearly below 2 (Figure 8A, Supplementary Table S1I).

In the presence of verapamil, SNS-032 600 $\mathrm{nM}$ caused maximum RNA polymerase inhibition in SHEPrSNS-032 ${ }^{2000 \mathrm{nM}}$ cells $(32 \pm 4 \%$ activity relative to non-treated control). This effect was not further enhanced by increasing the SNS-032 concentration to $1200 \mathrm{nM}(31 \pm 5 \%$ activity relative to non-treated control) (Figure 8B, Supplementary Table S1J). In contrast to this, combined SHEP cell treatment with SNS-032 $600 \mathrm{nM}$ and verapamil reduced RNA polymerase activity to $22 \pm 3 \%$ relative to untreated control, which was further decreased by combined SNS-032 $1200 \mathrm{nM}$ and verapamil treatment to $16 \pm 3 \%$ (Figure 8B, Supplementary Table S1J).

A

B + verapamil $(10 \mu \mathrm{M})$

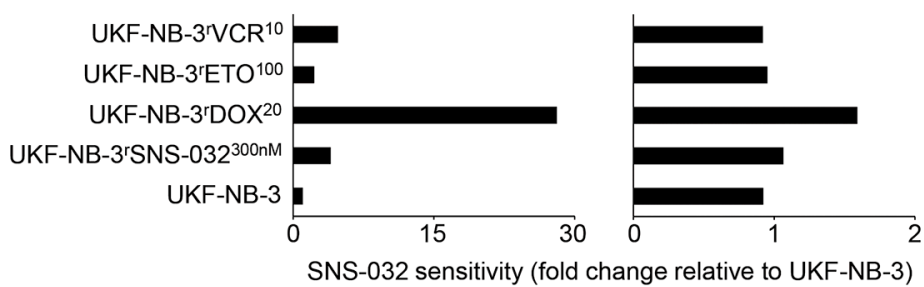

SNS-032 sensitivity (fold change relative to UKF-NB-3)

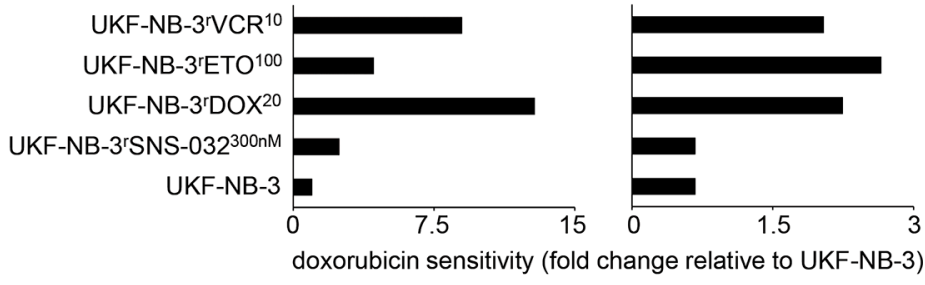

+ verapamil $(10 \mu \mathrm{M})$

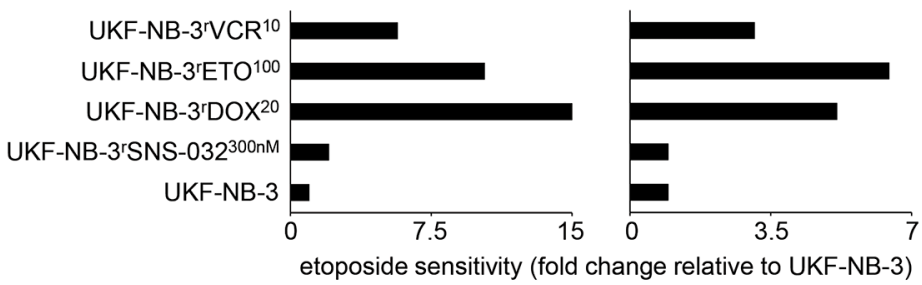

+ verapamil $(10 \mu \mathrm{M})$

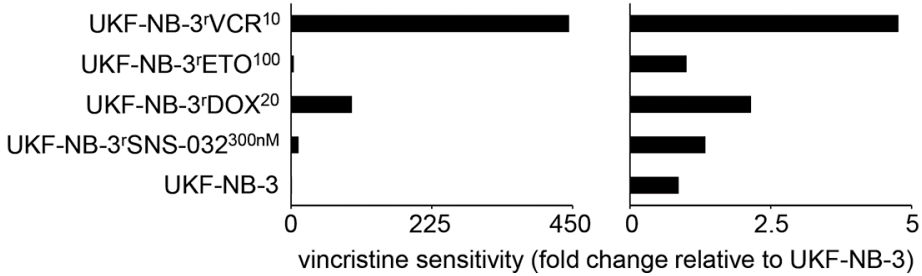

Figure 3: Relative sensitivity of UKF-NB-3 and its ABCB1-expressing sub-lines with acquired resistance to SNS-032 (UKF-NB-3 ${ }^{r}$ SNS-032 ${ }^{300 n M}$ ), doxorubicin (UKF-NB-3 ${ }^{r}$ DOX ${ }^{20}$ ), etoposide (UKF-NB-3 ${ }^{\text {ETO }}{ }^{100}$ ), and vincristine (UKFNB-3 ${ }^{r} V C R^{10}$ ) to the cytotoxic $A B C B 1$ substrates SNS-032, doxorubicin, etoposide, and vincristine in the absence or presence of the $\mathbf{A B C B 1}$ inhibitor verapamil. (A) Fold change $\mathrm{IC}_{50}$ investigated cell line/ $\mathrm{IC}_{50}$ UKF-NB-3; (B) Fold change $\mathrm{IC}_{50}$ investigated cell line in the presence of verapamil $(10 \mu \mathrm{M}) / \mathrm{IC}_{50} \mathrm{UKF}-\mathrm{NB}-3$. 
The positive control actinomycin D $100 \mathrm{ng} / \mathrm{mL}$, which is also an ABCB1 substrate [28] and interferes with RNA polymerase activity through DNA intercalation independently of CDK7 and CDK9 [29, 30], exerted the same activity in SHEP cells $(19.1 \pm 2.9 \%$ relative to untreated control) and SHEPrSNS-032 ${ }^{2000 \mathrm{nM}}$ cells $(19.5$ $\pm 2.8 \%$ relative to untreated control) in the presence of verapamil (Figure 8B, Supplementary Table S1J). These findings suggest that SHEPrSNS-032 ${ }^{2000 \mathrm{nM}}$ cells have developed mechanisms to specifically compensate SNS-032-mediated CDK7- and CDK9 inhibition.

\section{DISCUSSION}

To study acquired SNS-032 resistance mechanisms, we established two SNS-032-resistant neuroblastoma cell lines. Elevated ABCB1 expression represented, depending on the investigated cell line model, a dominant or even exclusive acquired SNS-032 resistance mechanism. In the clinics, few neuroblastomas appear to express ABCB1 at diagnosis [31]. However, ABCB1 expression might represent an acquired resistance mechanism in neuroblastoma [32]. In addition, ABCB1 expression may be an SNS-032-associated acquired resistance mechanism in neuroblastoma. Drug-adapted cancer cell lines were previously successfully used to identify novel clinically relevant acquired drug resistance mechanisms [33-37].

The resistance status of the SNS-032-resistant

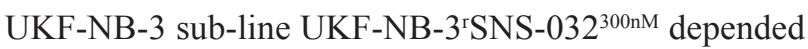
exclusively on $\mathrm{ABCB} 1$ function. $\mathrm{ABCB} 1$ inhibition completely re-sensitized UKF-NB- $3^{\text {rSNS}}-032^{300 \mathrm{nM}}$ to SNS-032 to the level of UKF-NB-3 cells. The same observation was made for UKF-NB- ${ }^{\text {r SNS }}-032^{300 \mathrm{nM}}$ cell sensitivity to the ABCB1 substrates doxorubicin, etoposide, and vincristine. UKF-NB- ${ }^{\text {r SNS }}-032^{300 \mathrm{nM}}$ cells displayed cross-resistance to these agents but their sensitivity to these drugs returned to the levels of UKF-NB-3 in the presence of the ABCB1 inhibitor verapamil. Moreover, UKF-NB- $3^{\text {rSNS}}-032^{300 n M}$ cells did not display cross-resistance to the non-ABCB1 substrate cisplatin or the alternative CDK inhibitors seliciclib, LDC000067, BS-181, or alvocidib. Previous results had demonstrated that SNS-032 reduces the viability of UKF-NB-3 cells (and other cancer cells) via interference with CDK7 and CDK9 and subsequent RNA polymerase II inhibition resulting in depletion of anti-apoptotic proteins with a high turnover rate including Mcl-1, XIAP, and survivin $[7,8,19]$. In the presence of the ABCB1

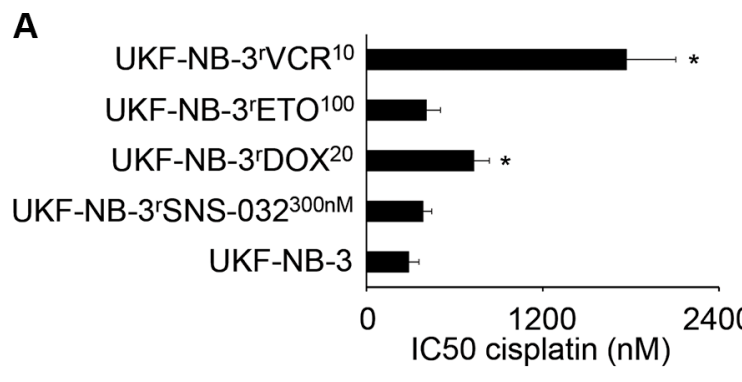

B
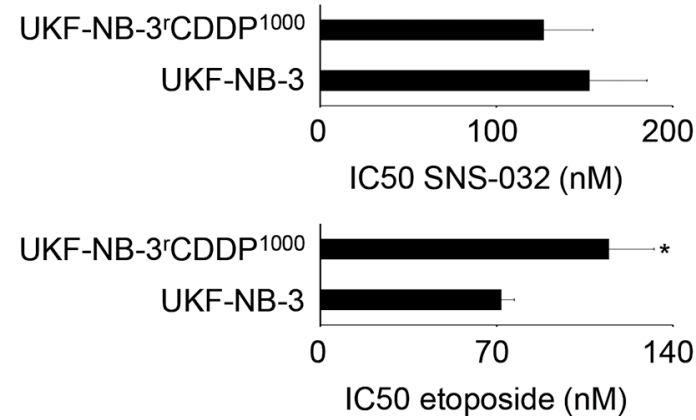

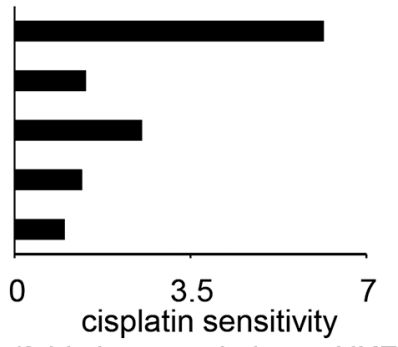

(fold change relative to UKFNB-3)

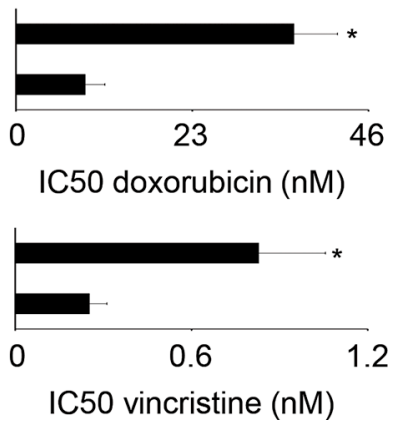

Figure 4: Sensitivity of UKF-NB-3 and its ABCB1-expressing sub-lines with acquired resistance to SNS-032 (UKF-NB$3^{r}$ SNS-032 $\left.{ }^{300 n M}\right)$, doxorubicin (UKF-NB-3 $\left.{ }^{r} D O X^{20}\right)$, etoposide (UKF-NB-3 ${ }^{r}$ TO $^{100}$ ), and vincristine $\left(U K F-N B-3^{r} V C R^{10}\right.$ ) to the non-ABCB1 substrate cisplatin, and sensitivity of the non ABCB1-expressing cisplatin-resistant UKF-NB-3 sub-line UKF-NB-3 ${ }^{r}$ CDDP ${ }^{1000}$ to the ABCB1 substrates SNS-032, doxorubicin, etoposide, and vincristine. (A) Cisplatin concentrations that reduce cell viability by $50 \%\left(\mathrm{IC}_{50}\right)$ and relative cisplatin sensitivity in drug-resistant UKF-NB-3 sub-lines relative to UKF-NB-3, numerical values are presented in Supplementary Table S1D. ${ }^{*} P<0.05$ relative to UKF-NB-3; (B) $\mathrm{IC}_{50}$ values for SNS032, doxorubicin, etoposide, or vincristine in UKF-NB-3 or UKF-NB-3 ${ }^{\mathrm{r}} \mathrm{CDDP}{ }^{1000}$ cells, numerical values are presented in Supplementary Table S1E. $* P<0.05$ relative to UKF-NB-3. 
inhibitor verapamil, SNS-032 exerted similar effects on CDK7, CDK9, and RNA polymerase II activity as well as on the cellular levels of Mcl-1, XIAP, and survivin in UKF-NB-3 ${ }^{\mathrm{r} S N S}-032^{300 \mathrm{nM}}$ and in UKF-NB-3 cells. Moreover, UKF-NB-3 ${ }^{\mathrm{r} S N S}-032^{300 \mathrm{nM}}$ and UKF-NB-3 cells did not differ in their sensitivity to siRNA-mediated depletion of CDK7 and CDK9. Taken together, these findings demonstrate that $\mathrm{ABCB} 1$ expression represents an exclusive resistance mechanism in UKF-NB-3 ${ }^{\text {r SNS- }}$ $032^{300 \mathrm{nM}}$ cells.

ABCB1 expression as sole resistance mechanism is unusual even among UKF-NB-3 sub-lines with acquired resistance to $\mathrm{ABCB} 1$ substrates. The $\mathrm{ABCB} 1$-expressing drug-resistant UKF-NB-3 sub-lines UKF-NB- $3^{\mathrm{r}} \mathrm{DOX}{ }^{20}$, UKF-NB- ${ }^{r} E^{2} O^{100}$, and UKF-NB- $3^{r} V_{C R}{ }^{10}$ maintained a substantial level of resistance to the respective drug of adaptation even when ABCB1 was inhibited. In addition, UKF-NB- $3^{\mathrm{r} D O X}{ }^{20}$ and UKF-NB- $3^{\mathrm{r}} \mathrm{VCR}^{10}$ cells were (in contrast to UKF-NB-3rSNS-032 ${ }^{300 \mathrm{nM}}$ cells) less sensitive to the non-ABCB1 substrate cisplatin than UKFNB-3 cells. These findings demonstrate that UKF-NB$3^{\mathrm{r}} \mathrm{DOX}^{20}$, UKF-NB- $3^{\mathrm{r}} \mathrm{VCR}^{10}$, and UKF-NB- $3^{\mathrm{r}} \mathrm{ETO}^{100}$ cells have developed further resistance mechanisms in addition to increased ABCB1 expression.

The investigation of the second SNS-032-resistant neuroblastoma cell line SHEPrSNS-032 $2000 \mathrm{nM}$ resulted in slight but noticeable differences. We had selected the neuroblastoma cell line SHEP as additional model for our study because it differs in two crucial parameters from UKF-NB-3: 1) SHEP cells do not harbor a MYCN

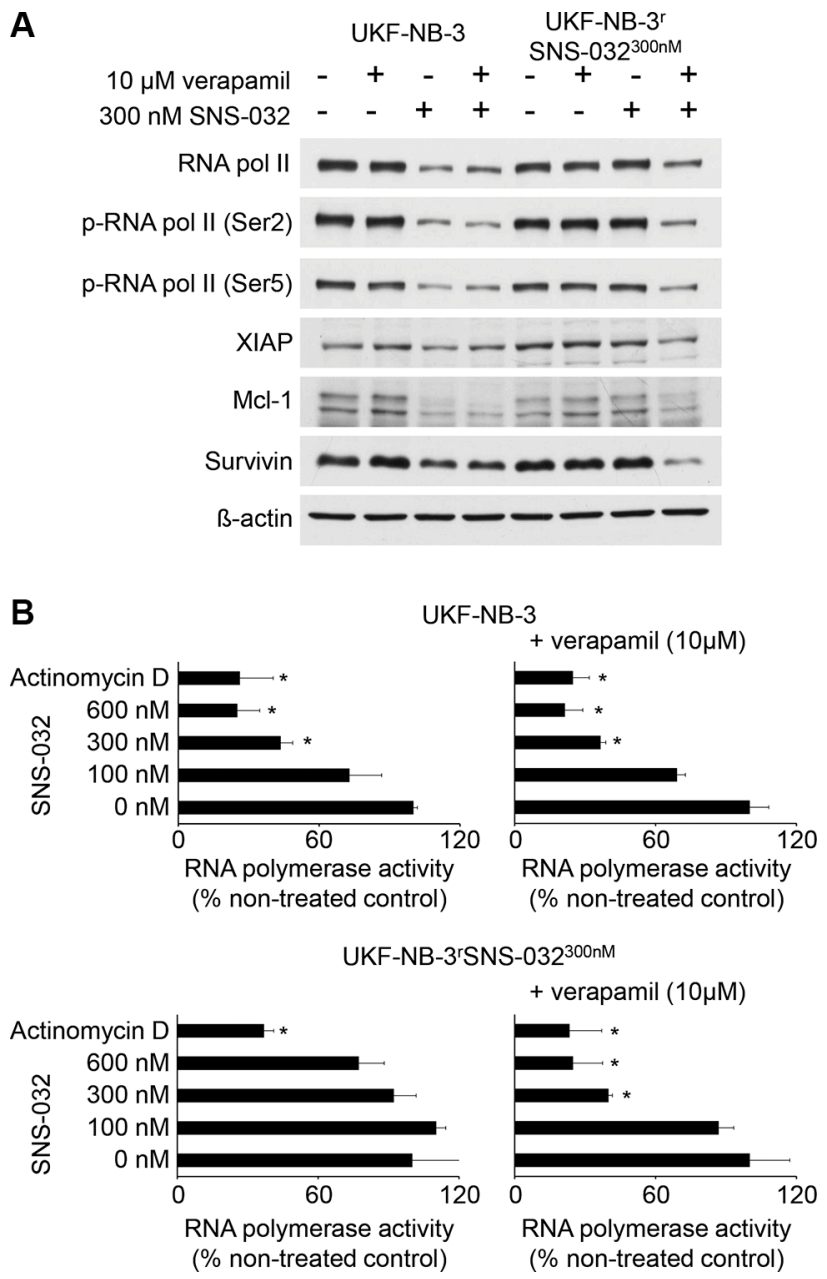

Figure 5: Effects of SNS-032 on CDK7 and CDK9 signalling and RNA polymerase activity in UKF-NB-3 and UKFNB-3rSNS-032 ${ }^{300 \mathrm{nM}}$ cells in the absence or presence of the ABCB1 inhibitor verapamil. (A) Cropped Western blots indicating RNA polymerase II protein levels, RNA polymerase II phosphorylation at Ser-5 (target of CDK7), RNA polymerase II phosphorylation at Ser-2 (target of CDK9), and levels of anti-apoptotic proteins with a high rate (XIAP, Mcl-1, survivin) in UKF-NB-3 and UKF-NB-3 ${ }^{\text {rSNS- }}$ $032^{300 \mathrm{nM}}$ cells after $24 \mathrm{~h}$ of incubation. $\beta$-actin served as loading control. (B) Effects of SNS-032 on the RNA polymerase activity in UKFNB-3 and UKF-NB-3 ${ }^{\mathrm{r} S N S}-032^{300 \mathrm{nM}}$ cells in the absence or presence of the ABCB1 inhibitor verapamil after $6 \mathrm{~h}$ of incubation. Actinomycin D $100 \mathrm{ng} / \mathrm{mL}$ served as positive control. ${ }^{*} P<0.05$ relative to non-treated control. 
amplification, a major marker of high-risk neuroblastoma $[1,2]$, and 2) SHEP cells are characterized by intrinsic ABCB1 expression. SHEPrSNS-032 $2^{2000 \mathrm{nM}}$ cells retained some low-level resistance to SNS-032 and doxorubicin (about 2-fold decreased sensitivity compared to SHEP) and some more pronounced resistance to etoposide (2.9-fold relative to SHEP) also in the presence of verapamil. This demonstrates that SHEPrSNS-032 $2^{2000 \mathrm{nM}}$ cells have acquired other resistance mechanisms in addition to ABCB1 expression. SNS-032 also exerted decreased effects on RNA polymerase activity in SHEP ${ }^{r}$ NSS- $032^{2000 \mathrm{nM}}$ cells than in SHEP cells when ABCB1 was inhibited. However, both cell lines displayed in the presence of the ABCB1 inhibitor verapamil the same sensitivity to RNA polymerase inhibition by actinomycin $\mathrm{D}$ that is also an ABCB1 substrate [28] and interferes with RNA polymerase activity by CDK7- and CDK9-independent mechanisms [29, 30]. These findings are again in contrast to observations in UKF-NB-3 ${ }^{\mathrm{r} S N S}-032^{300 \mathrm{nM}}$ cells and indicate that SHEPrSNS-032 ${ }^{2000 \mathrm{nM}}$ cells developed mechanisms to bypass SNS-032-induced CDK7 and 9 inhibition and subsequent RNA polymerase activity but no general resistance to RNA polymerase inhibition. This specific resistance to RNA polymerase inhibition via interference with CDK7 and 9 also confirms CDK7 and 9 as critical drug targets of SNS-032 in neuroblastoma that was previously suggested [19]. Hence, drug-adapted cells can be used to identify and confirm drug mechanisms of action.
A likely explanation for the differences observed between the resistance phenotypes of UKF-NB$3^{\mathrm{r} S N S}-032^{300 \mathrm{nM}}$ and SHEPrSNS-032 $2^{2000 \mathrm{nM}}$ cells is that SHEPrSNS-032 $2000 \mathrm{nM}$ cells were adapted to higher SNS032 concentrations. While non-ABCB1 expressing UKFNB-3 cells are highly sensitive to SNS-032 ( $\left.\mathrm{IC}_{50} 153 \mathrm{nM}\right)$, ABCB1-expressing SHEP cells display an $\mathrm{IC}_{50}$ value of $912 \mathrm{nM}$, which is above the therapeutically achievable SNS-032 plasma concentration of 754 nM [14]. Therefore, SHEP cells were adapted to growth in the presence of a much higher SNS-032 concentration (2000 nM) than UKF-NB-3 cells (300 nM). The SNS-032 $\mathrm{IC}_{50}$ of UKFNB-3 ${ }^{\text {rSNS}}-032^{300 \mathrm{nM}}$ cells $(607 \mathrm{nM})$ remained below the SNS-032 $\mathrm{IC}_{50}$ of parental SHEP cells, whereas the SNS$032 \mathrm{IC}_{50}$ of SHEPrSNS-032 $2^{2000 \mathrm{nM}}$ cells $(5045 \mathrm{nM})$ was about 8 -fold higher than that of UKF-NB- $3^{\text {rSNS- }} 032^{300 \mathrm{nM}}$ cells. Thus, it does not appear implausible that UKF-NB$3^{\mathrm{r} S N S}-032^{300 \mathrm{nM}}$ cells might develop additional resistance mechanisms if they were further adapted to higher SNS032 concentrations.

It remains unclear why SHEPrSNS-032 $2^{2000 \mathrm{nM}}$ cells did not display cross-resistance to the other CDK inhibitors investigated. It is known that kinase inhibitors designed to interfere with the same or similar targets may substantially differ in their overall pharmacological profiles (with regards to kinase inhibition as well as other structures) [8, $10,38-42]$. Hence, the lack of cross-resistance may not be too surprising. The inhibitory profiles of the different

A
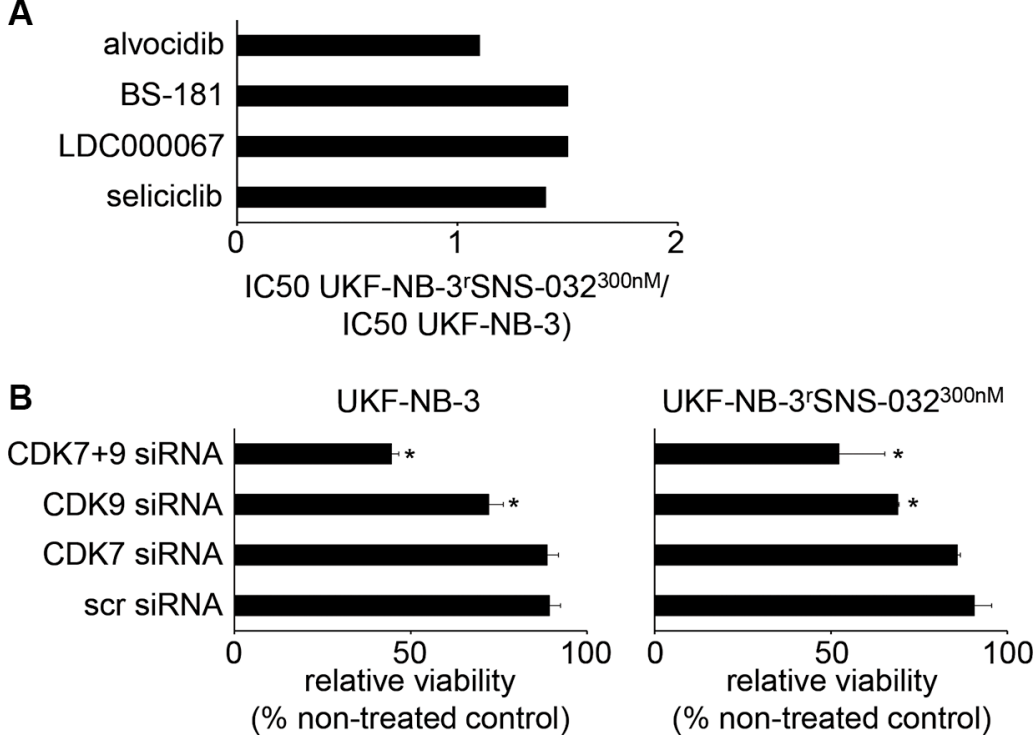

Figure 6: Sensitivity of UKF-NB-3 and its sub-line with acquired resistance to SNS-032 (UKF-NB-3 ${ }^{\text {rSNS-032 }}{ }^{300 n M}$ ) to CDK inhibition by alternative inhibitors or by siRNA-mediated CDK depletion. (A) Relative sensitivity of UKF-NB-3 and UKF-NB-3 ${ }^{\text {SNNS}}-032^{300 \mathrm{nM}}$ to the CDK2, 7, and 9 inhibitor seliciclib, the CDK7 inhibitor LDC000067, the CDK9 inhibitor BS-181, or the CDK 1,2,4,6,7, and 9 inhibitor alvocidib. Numerical values are presented in Supplementary Table S1F. (B) Effects of siRNA-mediated depletion of CDK7, CDK9, or CDK7 and CDK9 on UKF-NB-3 and UKF-NB-3 ${ }^{\text {rSNS-032 }}{ }^{300 \mathrm{nM}}$ cell viability as determined by MTT assay 72 h post-transfection. Non-targeting 'scrambled' siRNA (scr siRNA) served as control. Western blots indicating siRNA-mediated effects on protein levels are presented in Supplementary Figure S6. Numerical values are presented in Supplementary Table S1G. ${ }^{*} P<0.05$ relative to scr siRNA. 
CDK inhibitors differ with regard to their CDK inhibitory profiles. Seliciclib interferes (in contrast to SNS-032) with CDK5 in addition to CDK2, CDK7, and CDK9 [24, 43]. BS-181 does in contrast to SNS-032 not inhibit CDK9 [26]. LDC000067 was introduced as selective CDK9 inhibitor with negligible affinity to alternative CDKs [25]. Alvocidib is a broad spectrum CDK inhibitor acting on CDKs 1, 2, 4, 6, 7, and 9 [27].

Notably, cisplatin-resistant (UKF-NB- $3^{\mathrm{r}} \mathrm{CDDP}^{1000}$ ), doxorubicin-resistant (UKF-NB- $\left.3^{\mathrm{r}} \mathrm{DOX}{ }^{20}\right)$, and vincristine-resistant (UKF-NB- ${ }^{r} \mathrm{VCR}^{10}$ ) UKF-NB-3 sub-lines remained sensitive to seliciclib, LDC000067, BS-181, and alvocidib (Supplementary Table S1K) further supporting a possible role of CDKs as drug targets in neuroblastoma including therapy-refractory disease as previously suggested [17-19]. The alvocidib $\mathrm{IC}_{50} \mathrm{~s}$ were below $400 \mathrm{nM}$. In phase I clinical trials, steady-state plasma alvocidib concentrations $>400 \mu \mathrm{M}$ were achieved in human patients [44].

In conclusion, we show that $\mathrm{ABCB} 1$ expression represents the predominant resistance mechanism in neuroblastoma cells with acquired resistance to SNS-032. Most strikingly (and in clear contrast to neuroblastoma cell lines with acquired resistance to other anti-cancer agents that are ABCB1 substrates), $\mathrm{ABCB} 1$ expression is an exclusive resistance mechanism

A

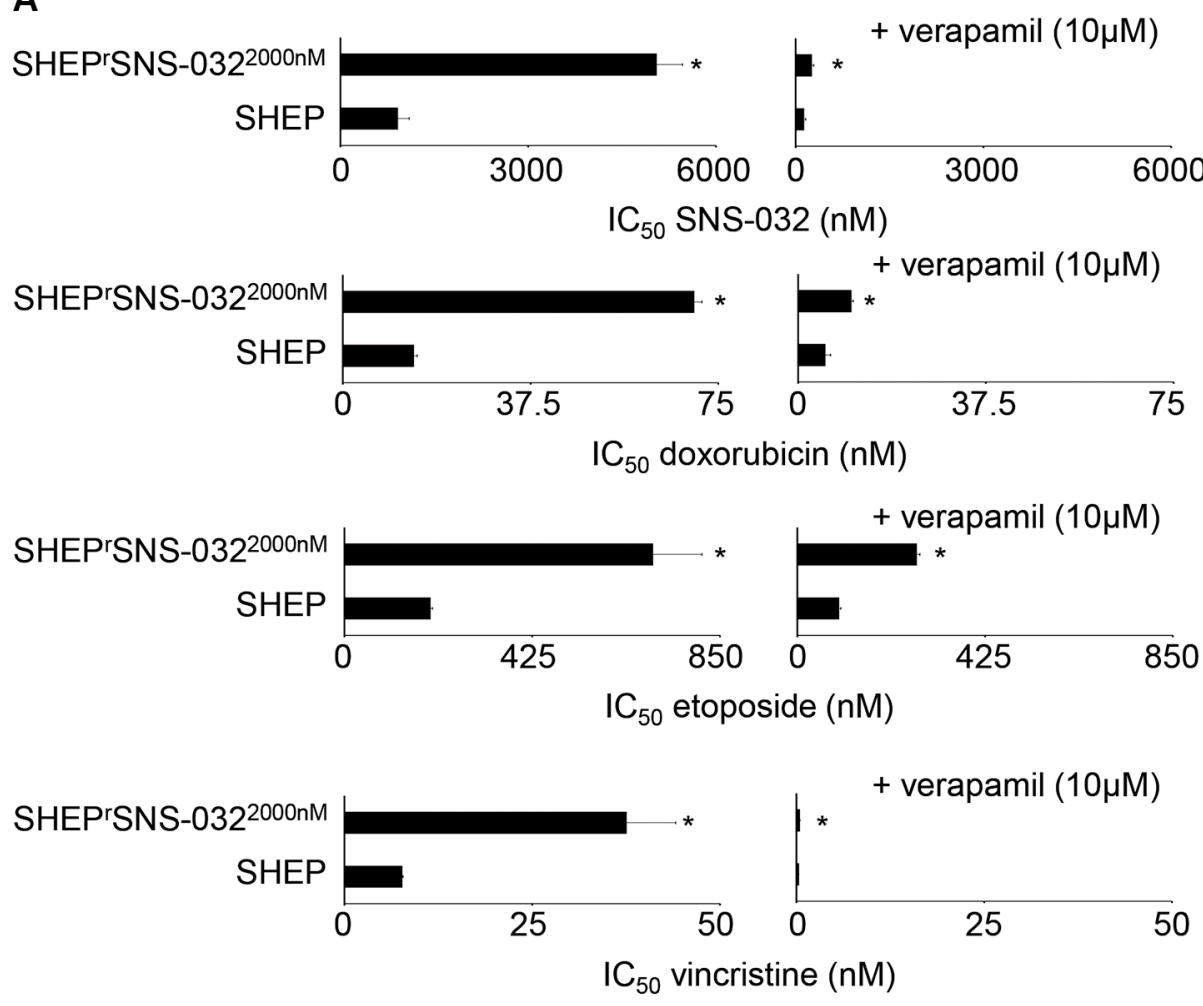

B

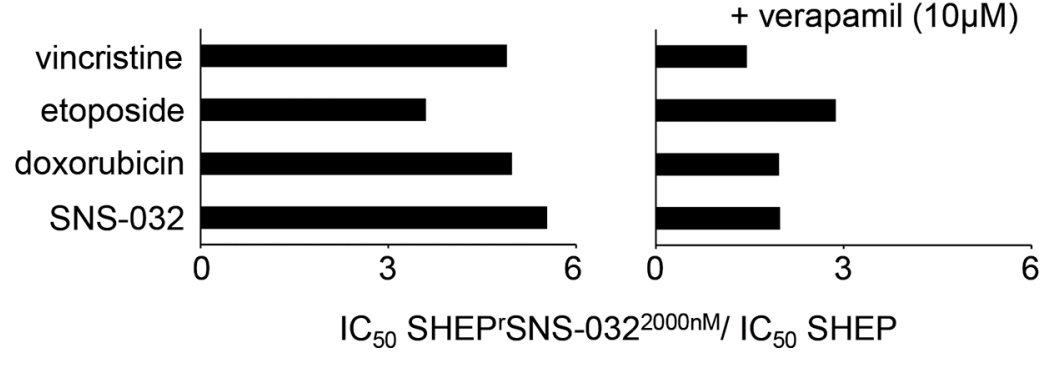

Figure 7: Sensitivity of SHEP and its sub-line with acquired resistance to SNS-032 (SHEPrSNS-032 ${ }^{2000 \mathrm{nM})}$ to the cytotoxic ABCB1 substrates SNS-032, doxorubicin, etoposide, and vincristine. (A) Concentrations that reduce cell viability by $50 \%\left(\mathrm{IC}_{50}\right)$ in the absence or presence of the $\mathrm{ABCB} 1$ inhibitor verapamil. Verapamil alone did not influence cell viability. ${ }^{*} P<0.05$ relative to the drug concentration that reduces cell viability by $50 \%\left(\mathrm{IC}_{50}\right)$ in SHEP cells; $(\mathbf{B})$ Fold change $\mathrm{IC}_{50} \mathrm{SHEP}^{\mathrm{r} S N S}-032^{2000 \mathrm{~nm}} / \mathrm{IC}_{50}$ $\mathrm{SHEP}$ in the absence or presence of verapamil. Numerical values are presented in Supplementary Table S1H. 
in UKF-NB- $3{ }^{\mathrm{r}} \mathrm{SNS}-032^{300 \mathrm{nM}}$ cells and a predominant resistance mechanism in SHEPrSNS-032 $2000 \mathrm{nM}$ cells. Although selective ABCB1 inhibitors are available [45, 46], clinical trials were disappointing. Reasons included that ABCB1 transporter inhibition may affect $\mathrm{ABCB} 1$-expressing hematopoietic stem cells and the body distribution of drugs due to effects on ABCB1 present on tissue barriers (e.g. the blood-brain-barrier). Also cancer cells may express multiple ABC transporters $[45,46]$. However, ABCB1 expression represents the dominant (sometimes exclusive) resistance mechanism to SNS-032 in neuroblastoma. Therefore, ABCB1 inhibitors may be candidates for combination therapy with SNS-032 that increase SNS-032 efficacy through (re)sensitization of ABCB1-expressing cancer cells, possibly reducing resistance formation.

\section{MATERIALS AND METHODS}

\section{Drugs}

SNS-032, BS-181, and LDC000067 were purchased from Selleck Chemicals via BIOZOL GmbH (Eching, Germany), seliciclib from LC Laboratories (Woburn,
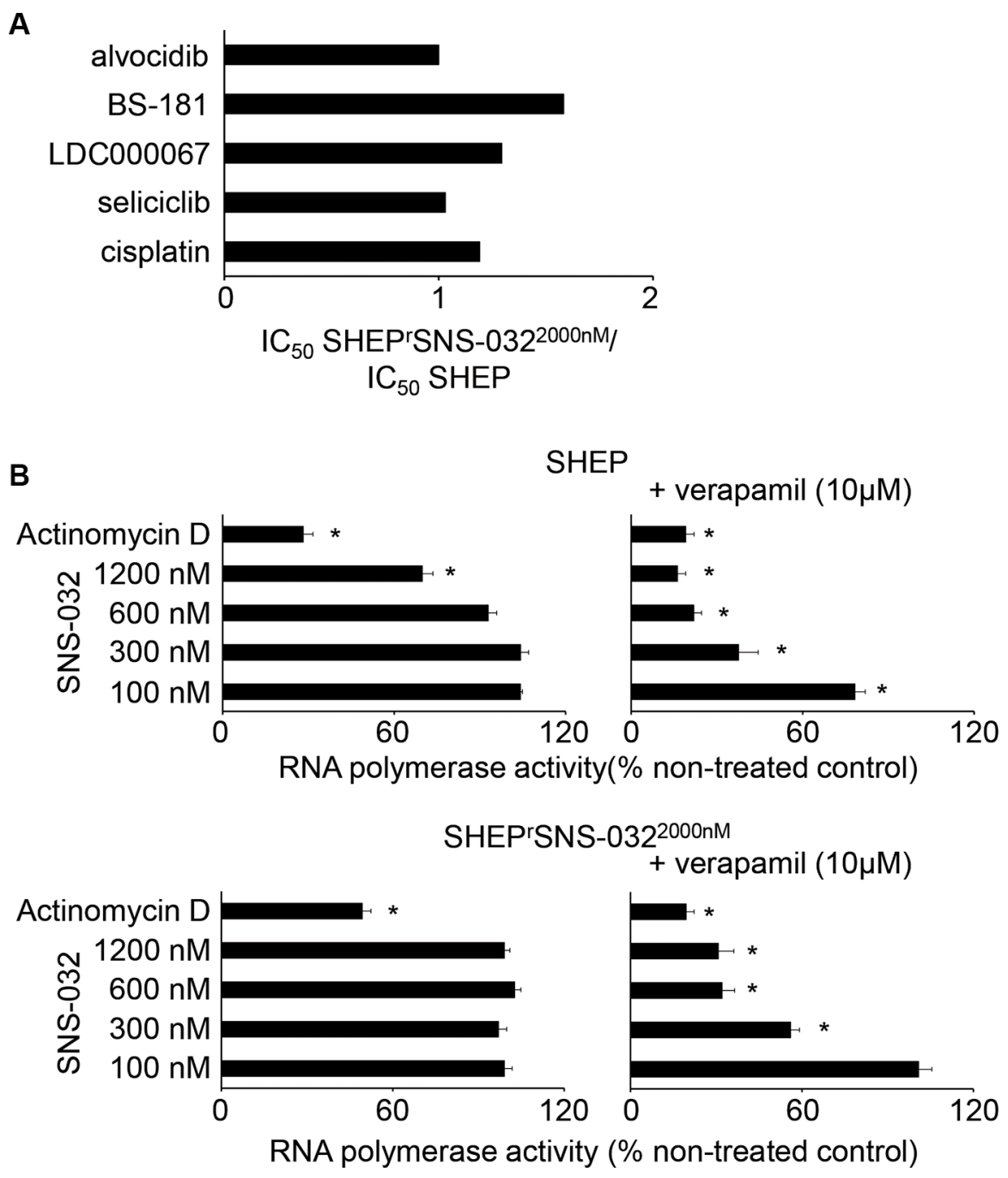

Figure 8: Sensitivity of SHEP and its sub-line with acquired resistance to SNS-032 (SHEPrSNS-032 2000nM) to the nonABCB1 substrates cisplatin, seliciclib (CDK2, 7, and 9 inhibitor), LDC000067 (CDK7 inhibitor), and BS-181 (CDK9 inhibitor). (A) Fold change $\mathrm{IC}_{50}$ SHEP SNS-032 $2000 \mathrm{~nm} / \mathrm{IC}_{50}$ SHEP; numerical values are presented in Supplementary Table S1K. (B) Effects of SNS-032 or actinomycin D $(100 \mathrm{ng} / \mathrm{mL})$ (interferes with RNA polymerase activity through DNA intercalation independently of CDK7 and CDK9) on RNA polymerase activity in SHEP and SHEPrSNS-032 ${ }^{2000 \mathrm{nM}}$ cells in the absence or presence of the ABCB1 inhibitor verapamil $(10 \mu \mathrm{M})$ as determined after $6 \mathrm{~h}$ of incubation. Numerical values are presented in Supplementary Table S1J. * $P<0.05$ relative to untreated control. 
Massachusetts), vincristine, cisplatin, and etoposide from TEVA GmbH (Radebeul, Germany), actinomycin D from Lundbeck Pharmaceuticals Ireland Limited (Dublin, Ireland), and verapamil from Sigma-Aldrich (Munich, Germany).

\section{Synthesis and characterisation of SNS-032- BODIPY}

SNS-032-BODIPY was synthesized using SNS-032 (Selleck Chemicals) and BDP-FL-NHS-ester (Lumiprobe, Hannover, Germany) (Supplementary Figure S7A). All other reagents and solvents were purchased from Fisher Scientific (Loughborough, UK). NMR spectra were collected on a JEOL $400 \mathrm{MHz}$. HRMS were collected on a Bruker MicroTOFQ spectrometer by direct injection with a $\mathrm{MeOH} / \mathrm{HCOOH}$ matrix. Excitation and emission spectra were collected on an Edinburgh Instruments FS-5 spectrofluorimeter. HPLC traces were collected on a Dionex U3000 HPLC apparatus.

To $7.68 \mathrm{mg}\left(2.02 \times 10^{-2} \mathrm{mmol}\right)$ of SNS-032 chloroform $(1.3 \mathrm{~mL})$ was added and the mixture sonicated until dossolution. BDP-FL NHS ester (purchased from Lumiprobe; $8.09 \mathrm{mg}, 2.08 \times 10^{-2} \mathrm{mmol}$ ) was also dissolved in chloroform $(1.3 \mathrm{~mL})$ and sonicated to ensure dissolution. The SNS-032 mixture was added to BDPFL and the resulting sample was sonicated for $1 \mathrm{~h}$. Reaction was monitored using thin-layer chromatography (dichloromethane: methanol - 4:0.1; product rf: 0.21). Reaction mixture was concentrated and then purified by preparative TLC using the above noted eluent. The adsorbed product band on the silica plate was scraped, isolated and rinsed repeatedly with acetonitrile to extract the product yielding $9.0 \mathrm{mg}\left(1.38 \times 10^{-2} \mathrm{mmol}\right.$; $\left.68 \%\right)$. Purity was confirmed by reverse-phase HPLC (Figure 7B-7E).

${ }^{1} \mathrm{H}$ NMR (400 MHz, $\left.\mathrm{CDCl}_{3}\right)$ : d 7.33 (s, 1H, Ar-H), 7.13 (s, 1H, Ar-H), 6.93 (d, $J=4.2 \mathrm{~Hz}, 1 \mathrm{H}, \mathrm{Ar}-\mathrm{H}), 6.61$ (s, 1H, Ar-H), 6.35 (d, J=4.2 Hz, 1H, Ar-H), 6.11 (s, 1H, Csp2-H), 5.33 (bs, 1H, NH), 3.96 (s, 2H), 4.05 (bd, $J=$ $15.1 \mathrm{~Hz}, 2 \mathrm{H}), 3.32$ (t, $J=7.8 \mathrm{~Hz}, 2 \mathrm{H}), 3.12(\mathrm{t}, J=15.1 \mathrm{~Hz}$, $2 \mathrm{H}), 2.80(\mathrm{t}, J=7.8 \mathrm{~Hz}, 2 \mathrm{H}), 2.63(\mathrm{~m}, 1 \mathrm{H}), 2.58(\mathrm{~s}, 3 \mathrm{H})$, $2.27(\mathrm{~s}, 3 \mathrm{H}), 1.96(\mathrm{~m}, 2 \mathrm{H}), 1.73(\mathrm{~m}, 2 \mathrm{H}) .{ }^{19} \mathrm{~F}$ NMR $(376$ MHz, DMSO- $\left.d_{6}\right):-145.675$ (q, $\left.J_{\mathrm{F}-\mathrm{B}}=31.4 \mathrm{~Hz}\right) .{ }^{11} \mathrm{~B}$ NMR $\left(128 \mathrm{MHz}, \mathrm{DMSO}-d_{6}\right):-1.7\left(\mathrm{t}, J_{\mathrm{B}-\mathrm{F}}=31 \mathrm{~Hz}\right) \mathrm{HRMS}: m / z$ $(\mathrm{M}+\mathrm{H})$ calcd. $=655.2508$, found $=655.2562 ; \mathrm{m} / \mathrm{z}\left(\mathrm{M}-{ }^{19} \mathrm{~F}\right)$ calcd. $=635.2446$, found $=635.2492$.

\section{Cell lines}

The MYCN-amplified neuroblastoma cell line UKF-NB-3 was established from a stage 4 neuroblastoma patient [44]. SHEP cells [45] were kindly provided by Dr. Angelika Eggert (Universität Duisburg-Essen, Germany). Neuroblastoma cell lines were adapted to growth in the presence of anti-cancer drugs by continuous exposure to increasing drug concentrations as described previously $[19,47,49]$. All neuroblastoma cell lines with acquired drug resistance were derived from the resistant cancer cell line (RCCL) collection. The corresponding IC50 values for the parental cells and their drug-resistant sub-lines were provided previously $[19,50]$. All cells were propagated in IMDM supplemented with $10 \%$ fetal calf serum (FCS), $100 \mathrm{IU} / \mathrm{ml}$ penicillin, and $100 \mu \mathrm{g} / \mathrm{ml}$ streptomycin at $37^{\circ} \mathrm{C}$. Cells were routinely tested for mycoplasma contamination and authenticated by short tandem repeat profiling.

UKF-NB-3 cells were transduced with lentiviral vectors encoding for ABCB1 (also known as MDR1 or P-glycoprotein) or ABCG2 (also known as BCRP) as described previously $[50,51]$ using the Lentiviral Gene Ontology (LeGO) vector technology [52] (www.lentigovectors.de).

\section{Viability assay}

Cell viability was tested either by the 3-(4,5-dimethylthiazol-2-yl)-2,5-diphenyltetrazolium bromide (MTT) dye reduction assay after $120 \mathrm{~h}$ incubation modified as described previously $[47,50]$.

\section{Determination of $\mathrm{ABCB} 1, \mathrm{ABCG} 2$, and $\mathrm{ABCC1}$ expression}

The ABC-transporters ABCB1, ABCC1, and ABCG2 were detected by flow cytometry as described previously [51] using specific primary antibodies against ABCB1 (Alexis Biochemicals via AXXORA Deutschland, Lörrach, Germany), ABCC1, and ABCG2 (Kamiya Biomedical Company, Seattle, Washington) and secondary phycoerythrin(PE)-labelled goat anti-mouse antibody (PE, R\&D Systems, Wiesbaden, Germany).

\section{RNA interference experiments}

Synthetic siRNAoligonucletides targeting CDK7, CDK9, ABCC1, or ABCB1 (ONTARGETplusSMARTpoolsiRNAs) were purchased from Dharmacon (Lafayette, CO, USA). The non-targeting siRNA ON-TARGETplusSMARTpool (Dharmacon) was used as negative control. Transfections were performed using the Neon $^{\mathrm{TM}}$ Transfection System (Invitrogen, Darmstadt, Germany) according to the manufacturer's protocol. UKF-NB-3 cells or UKF-NB-3 ${ }^{\text {rSNS- }}$ $032^{300 \mathrm{nM}}$ cells were grown to about $60-80 \%$ confluence, trypsinized and $2 \times 10^{6}$ cells were re-suspended in $200 \mu \mathrm{l}$ of resuspension buffer containing $2.5 \mu \mathrm{M}$ siRNA. Electroporation was performed in a pipette tip chamber with previously optimized adjustments (voltage 1400, width 20, 2 pulses). After electroporation, the cells were transferred into fibronectin $(100 \mu \mathrm{g} / \mathrm{ml})$-coated well plates containing pre-warmed IMDM plus $10 \%$ FCS. 


\section{Western blot}

Cells were lysed in Triton X-sample buffer and separated by SDS-PAGE. Proteins were detected using specific antibodies directed against $\beta$-actin (BioVision via BioCat $\mathrm{GmbH}$, Heidelberg, Germany), ABCC1, ABCG2 (both from Santa Cruz Biotechnology, Heidelberg, Germany), ABCB1, XIAP, Mcl-1, CDK7, CDK9 (all from Cell Signaling via New England Biolabs, Frankfurt am Main, Germany), RNA polymerase II, Ser2phosphorylated RNA polymerase II, Ser5-phosphorylated RNA polymerase II (all from Abcam, Cambridge, UK), and survivin (R\&D Systems, Wiesbaden, Germany). Protein bands were visualized by enhanced chemiluminescence using a commercially available kit (Thermo Scientific, Schwerte, Germany).

\section{Flow cytometry}

Cells were incubated with SNS-032-BODIPY for 45 $\min$ at $37^{\circ} \mathrm{C}$. Then, the cells were washed twice with PBS before fresh medium was added. The cellular fluorescence was analysed after a further 120 minutes using a FACS Canto (BD Biosciences, Heidelberg, Germany) using the FL1 channel. In verapamil-treated cells, verapamil was continuously present throughout the experiments including a pre-incubation period of 30 minutes at $37^{\circ} \mathrm{C}$ prior to the addition of SNS-032-BODIPY.

\section{RNA synthesis assay}

Detection of global RNA synthesis was performed as previously described [19] using the Click-iT ${ }^{\circledR}$ RNA HCS Assay (Invitrogen, Darmstadt, Germany).

\section{ACKNOWLEDGMENTS}

The authors thank Kristoffer Riecken and Boris Fehse (Universitätsklinikum Hamburg-Eppendorf) for provision of and support with LeGO vectors.

\section{CONFLICTS OF INTEREST}

Nothing to declare.

\section{GRANT SUPPORT}

The work was supported by the charity Hilfe für krebskranke Kinder Frankfurt e.V., its trust Frankfurter Stiftung für krebskranke Kinder (J.C.), and the Kent Cancer Trust (M.M.).

\section{REFERENCES}

1. Morgenstern DA, Baruchel S, Irwin MS. Current and future strategies for relapsed neuroblastoma: challenges on the road to precision therapy. J Pediatr Hematol Oncol. 2013; 35:337-347.

2. Park JR, Bagatell R, London WB, Maris JM, Cohn SL, Mattay KK, Hogarty M; COG Neuroblastoma Committee. Children's Oncology Group's 2013 blueprint for research: neuroblastoma. Pediatr Blood Cancer. 2013; 60:985-993.

3. Misra RN, Xiao HY, Kim KS, Lu S, Han WC, Barbosa SA, Hunt JT, Rawlins DB, Shan W, Ahmed SZ, Qian L, Chen BC, Zhao R, et al. N-(cycloalkylamino)acyl-2aminothiazole inhibitors of cyclin-dependent kinase 2 . $\mathrm{N}$-[5-[[[5-(1,1-dimethylethyl)-2-oxazolyl]methyl]thio]2-thiazolyl]-4-piperidinecarboxamide (BMS-387032), a highly efficacious and selective antitumor agent. J Med Chem. 2004; 47:1719-1728.

4. Mukhopadhyay P, Ali MA, Nandi A, Carreon P, Choy H, Saha D. The cyclin-dependent kinase 2 inhibitor downregulates interleukin-1beta-mediated induction of cyclooxygenase-2 expression in human lung carcinoma cells. Cancer Res. 2006; 66:1758-1766.

5. Scrace SF, Kierstan P, Borgognoni J, Wang LZ, Denny S, Wayne J, Bentley C, Cansfield AD, Jackson PS, Lockie AM, Curtin NJ, Newell DR, Williamson DS, et al. Transient treatment with CDK inhibitors eliminates proliferative potential even when their abilities to evoke apoptosis and DNA damage are blocked. Cell Cycle. 2008; 7:3898-3907.

6. Ali MA, Choy H, Habib AA, Saha D. SNS-032 prevents tumor cell-induced angiogenesis by inhibiting vascular endothelial growth factor. Neoplasia. 2007; 9:370-381.

7. Chen R, Wierda WG, Chubb S, Hawtin RE, Fox JA, Keating MJ, Gandhi V, Plunkett W. Mechanism of action of SNS-032, a novel cyclin-dependent kinase inhibitor, in chronic lymphocytic leukemia. Blood. 2009; 113:4637-4645.

8. Conroy A, Stockett DE, Walker D, Arkin MR, Hoch U, Fox JA, Hawtin RE. SNS-032 is a potent and selective CDK 2, 7 and 9 inhibitor that drives target modulation in patient samples. Cancer Chemother Pharmacol. 2009; 64:723-732.

9. Chen R, Chubb S, Cheng T, Hawtin RE, Gandhi V, Plunkett W. Responses in mantle cell lymphoma cells to SNS-032 depend on the biological context of each cell line. Cancer Res. 2010; 70:6587-6597.

10. Kruse U, Pallasch CP, Bantscheff M, Eberhard D, Frenzel L, Ghidelli S, Maier SK, Werner T, Wendtner CM, Drewes G. Chemoproteomics-based kinome profiling and target deconvolution of clinical multi-kinase inhibitors in primary chronic lymphocytic leukemia cells. Leukemia. 2011; 25:89-100.

11. Walsby E, Lazenby M, Pepper C, Burnett AK. The cyclin-dependent kinase inhibitor SNS-032 has single agent activity in AML cells and is highly synergistic with cytarabine. Leukemia. 2011; 25:411-419.

12. Wu Y, Chen C, Sun X, Shi X, Jin B, Ding K, Yeung SC, Pan J. Cyclin-dependent kinase 7/9 inhibitor SNS-032 abrogates FIP1-like-1 platelet-derived growth factor receptor $\alpha$ and bcr-abl oncogene addiction in malignant hematologic cells. Clin Cancer Res. 2012; 18:1966-1978. 
13. Boquoi A, Chen T, Enders GH. Chemoprevention of mouse intestinal tumorigenesis by the cyclin-dependent kinase inhibitor SNS-032. Cancer Prev Res (Phila). 2009; 2:800-806.

14. Heath EI, Bible K, Martell RE, Adelman DC, Lorusso PM. A phase 1 study of SNS-032 (formerly BMS-387032), a potent inhibitor of cyclin-dependent kinases 2, 7 and 9 administered as a single oral dose and weekly infusion in patients with metastatic refractory solid tumors. Invest New Drugs. 2008; 26:59-65.

15. Tong WG, Chen R, Plunkett W, Siegel D, Sinha R, Harvey RD, Badros AZ, Popplewell L, Coutre S, Fox JA, Mahadocon K, Chen T, Kegley P, et al. Phase I and pharmacologic study of SNS-032, a potent and selective Cdk2, 7, and 9 inhibitor, in patients with advanced chronic lymphocytic leukemia and multiple myeloma. J Clin Oncol. 2010; 28:3015-3022.

16. Robak P, Robak T. A Targeted Therapy for Protein and Lipid Kinases in Chronic Lymphocytic Leukemia. Curr Med Chem. 2012; 19:5294-5318.

17. Bettayeb K, Baunbæk D, Delehouze C, Loaëc N, Hole AJ, Baumli S, Endicott JA, Douc-Rasy S, Bénard J, Oumata N, Galons H, Meijer L. CDK Inhibitors Roscovitine and CR8 Trigger Mcl-1 Down-Regulation and Apoptotic Cell Death in Neuroblastoma Cells. Genes Cancer. 2010; 1:369-380. doi: 10.1177/1947601910369817.

18. Garrofé-Ochoa X, Cosialls AM, Ribas J, Gil J, Boix J. Transcriptional modulation of apoptosis regulators by roscovitine and related compounds. Apoptosis. 2011; 16:660-670.

19. Löschmann N, Michaelis M, Rothweiler F, Zehner R, Cinatl J, Voges Y, Sharifi M, Riecken K, Meyer J, von Deimling A, Fichtner I, Ghafourian T, Westermann F, et al. Testing of SNS-032 in a Panel of Human Neuroblastoma Cell Lines with Acquired Resistance to a Broad Range of Drugs. Transl Oncol. 2013; 6:685-696.

20. Kamath AV, Chong S, Chang M, Marathe PH. P-glycoprotein plays a role in the oral absorption of BMS387032, a potent cyclin-dependent kinase 2 inhibitor, in rats. Cancer Chemother Pharmacol. 2005; 55:110-116.

21. Cihalova D, Hofman J, Ceckova M, Staud F. Purvalanol A, olomoucine II and roscovitine inhibit ABCB1 transporter and synergistically potentiate cytotoxic effects of daunorubicin in vitro. PLoS One. 2013; 8:e83467.

22. Brodeur GM. Knowing your ABCCs: novel functions of ABCC transporters. J Natl Cancer Inst. 2011; 103:1207-1208.

23. Dantzig AH, Shepard RL, Cao J, Law KL, Ehlhardt WJ, Baughman TM, Bumol TF, Starling JJ. Reversal of P-glycoprotein-mediated multidrug resistance by a potent cyclopropyldibenzosuberane modulator, LY335979. Cancer Res. 1996; 56:4171-4179.

24. Aldoss IT, Tashi T, Ganti AK. Seliciclib in malignancies. Expert Opin Investig Drugs. 2009; 18:1957-1965.

25. Albert TK, Rigault C, Eickhoff J, Baumgart K, Antrecht C, Klebl B, Mittler G, Meisterernst M. Characterization of molecular and cellular functions of the cyclin-dependent kinase CDK9 using a novel specific inhibitor. $\mathrm{Br} \mathrm{J}$ Pharmacol. 2014; 171:55-68.

26. Ali S, Heathcote DA, Kroll SH, Jogalekar AS, Scheiper B, Patel H, Brackow J, Siwicka A, Fuchter MJ, Periyasamy M, Tolhurst RS, Kanneganti SK, Snyder JP, et al. The development of a selective cyclin-dependent kinase inhibitor that shows antitumor activity. Cancer Res. 2009; 69:6208-6215.

27. Blachly JS, Byrd JC. Emerging drug profile: cyclindependent kinase inhibitors. Leuk Lymphoma. 2013;54: 2133-2143.

28. Hill CR, Jamieson D, Thomas HD, Brown CD, Boddy AV, Veal GJ. Characterisation of the roles of ABCB1, ABCC1, $\mathrm{ABCC} 2$ and $\mathrm{ABCG} 2$ in the transport and pharmacokinetics of actinomycin $\mathrm{D}$ in vitro and in vivo. Biochem Pharmacol. 2013; 85:29-37.

29. Sobell HM. Actinomycin and DNA transcription. Proc Natl Acad Sci USA. 1985; 82:5328-5331.

30. Tani H, Akimitsu N. Genome-wide technology for determining RNA stability in mammalian cells: historical perspective and recent advantages based on modified nucleotide labeling. RNA Biol. 2012; 9:1233-1238.

31. Yu DM, Huynh T, Truong AM, Haber M, Norris MD. ABC transporters and neuroblastoma. Adv Cancer Res. 2015; 125:139-170.

32. Dhooge CR, De Moerloose BM, Benoit YC, Van Roy N, Philippé J, Laureys GG. Expression of the MDR1 gene product P-glycoprotein in childhood neuroblastoma. Cancer. 1997; 80:1250-1257.

33. Sharma SV, Haber DA, Settleman J. Cell line-based platforms to evaluate the therapeutic efficacy of candidate anticancer agents. Nat Rev Cancer. 2010; 10: 241-253.

34. Domingo-Domenech J, Vidal SJ, Rodriguez-Bravo V, Castillo-Martin M, Quinn SA, Rodriguez-Barrueco R, Bonal DM, Charytonowicz E, Gladoun N, de la IglesiaVicente J, Petrylak DP, Benson MC, Silva JM, et al. Suppression of acquired docetaxel resistance in prostate cancer through depletion of notch- and hedgehog-dependent tumor-initiating cells. Cancer Cell. 2012; 22:373-388.

35. Joseph JD, Lu N, Qian J, Sensintaffar J, Shao G, Brigham D, Moon M, Maneval EC, Chen I, Darimont B, Hager JH. A clinically relevant androgen receptor mutation confers resistance to second-generation antiandrogens enzalutamide and ARN-509. Cancer Discov. 2013; 3:1020-1029.

36. Korpal M, Korn JM, Gao X, Rakiec DP, Ruddy DA, Doshi S, Yuan J, Kovats SG, Kim S, Cooke VG, Monahan JE, Stegmeier F, Roberts TM, et al. An F876L mutation in androgen receptor confers genetic and phenotypic resistance to MDV3100 (enzalutamide). Cancer Discov. 2013; 3:1030-1043.

37. Bucheit AD, Davies MA. Emerging insights into resistance to BRAF inhibitors in melanoma. Biochem Pharmacol. 2014; 87:381-389. 
38. Michaelis M, Rothweiler F, Löschmann N, Sharifi M, Ghafourian T, Cinatl J Jr. Enzastaurin inhibits ABCB1mediated drug efflux independently of effects on protein kinase $\mathrm{C}$ signalling and the cellular p53 status. Oncotarget. 2015; 6:17605-20. doi: 10.18632/oncotarget.2889.

39. Karaman MW, Herrgard S, Treiber DK, Gallant $P$, Atteridge CE, Campbell BT, Chan KW, Ciceri P, Davis MI, Edeen PT, Faraoni R, Floyd M, Hunt JP, et al. A quantitative analysis of kinase inhibitor selectivity. Nat Biotechnol. 2008; 26:127-132.

40. Davis MI, Hunt JP, Herrgard S, Ciceri P, Wodicka LM, Pallares G, Hocker M, Treiber DK, Zarrinkar PP. Comprehensive analysis of kinase inhibitor selectivity. Nat Biotechnol. 2011; 29:1046-1051.

41. Hantschel O. Unexpected off-targets and paradoxical pathway activation by kinase inhibitors. ACS Chem Biol. 2015; 10:234-245.

42. Michaelis M, Rothweiler F, Nerreter T, Van Rikxoort M, Sharifi M, Wiese M, Ghafourian T, Cinatl J Jr. Differential effects of the oncogenic BRAF inhibitor PLX4032 (vemurafenib) and its progenitor PLX4720 on ABCB1 function. J Pharm Pharm Sci. 2014; 17:154-168.

43. Meijer L, Borgne A, Mulner O, Chong JP, Blow JJ, Inagaki $\mathrm{N}$, Inagaki $\mathrm{M}$, Delcros $\mathrm{JG}$, Moulinoux JP. Biochemical and cellular effects of roscovitine, a potent and selective inhibitor of the cyclin-dependent kinases cdc2, cdk2 and cdk5. Eur J Biochem. 1997; 243:527-536.

44. Thomas JP, Tutsch KD, Cleary JF, Bailey HH, Arzoomanian R, Alberti D, Simon K, Feierabend C, Binger K, Marnocha R, Dresen A, Wilding G. Phase I clinical and pharmacokinetic trial of the cyclin-dependent kinase inhibitor flavopiridol. Cancer Chemother Pharmacol. 2002; 50:465-472.

45. Szakács G, Paterson JK, Ludwig JA, Booth-Genthe C, Gottesman MM. Targeting multidrug resistance in cancer. Nat Rev Drug Discov. 2006; 5:219-234.
46. Binkhathlan Z, Lavasanifar A. P-glycoprotein inhibition as a therapeutic approach for overcoming multidrug resistance in cancer: current status and future perspectives. Curr Cancer Drug Targets. 2013; 13:326-346.

47. Kotchetkov R, Driever PH, Cinatl J, Michaelis M, Karaskova J, Blaheta R, Squire JA, Von Deimling A, Moog J, Cinatl J Jr. Increased malignant behavior in neuroblastoma cells with acquired multi-drug resistance does not depend on P-gp expression. Int J Oncol. 2005; 27:1029-1037.

48. Baker DL, Reddy UR, Pleasure D, Thorpe CL, Evans AE, Cohen PS, Ross AH. Analysis of nerve growth factor receptor expression in human neuroblastoma and neuroepithelioma cell lines. Cancer Res. 1989; 49:4142-4146.

49. Michaelis M, Rothweiler F, Barth S, Cinatl J, van Rikxoort M, Löschmann N, Voges Y, Breitling R, von Deimling A, Rödel F, Weber K, Fehse B, Mack E, et al. Adaptation of cancer cells from different entities to the MDM2 inhibitor nutlin-3 results in the emergence of p53mutated multi-drug-resistant cancer cells. Cell Death Dis. 2011; 2:e243.

50. Michaelis M, Agha B, Rothweiler F, Löschmann N, Voges Y, Mittelbronn M, Starzetz T, Harter PN, Abhari BA, Fulda S, Westermann F, Riecken K, Spek S. Identification of flubendazole as potential anti-neuroblastoma compound in a large cell line screen. Sci Rep. 2015; 5: 8202.

51. Michaelis M, Rothweiler F, Nerreter T, Sharifi M, Ghafourian T, Cinatl J. Karanjin interferes with ABCB1, ABCC1, and ABCG2. J Pharm Pharm Sci. 2014; 17:92-105.

52. Weber K, Bartsch U, Stocking C, Fehse B. A multicolor panel of novel lentiviral "gene ontology" (LeGO) vectors for functional gene analysis. Mol Ther. 2008; 16:698-706. 